\title{
CFD simulation of a cabin thermal environment with and without human body - thermal comfort evaluation
}

\author{
Paul Danca ${ }^{1,2}$, Florin Bode ${ }^{3}$, Ilinca Nastase $^{2, *}$ and Amina Meslem ${ }^{1, *}$ \\ ${ }^{1}$ IUT Rennes, Laboratoire Génie Civil Génie Mécanique 35704 Rennes Cedex 7 France \\ ${ }^{2}$ CAMBI Research Center, Technical University of Civil Engineering Bucharest, 021414 Bucharest, Romania \\ ${ }^{3}$ Technical University of Cluj Napoca, Department of Mechanical Engineering 400020 Cluj - Napoca, Romania
}

\begin{abstract}
Nowadays, thermal comfort became one of the criteria in choosing a vehicle. In last decades time spent by people in vehicles had risen substantially. During each trip, thermal comfort must to be ensured for a good psychological and physical state of the passengers. Also, a comfortable environment leads to a higher power concentration of the driver thereby to a safe trip for vehicle occupants and for all traffic participants. The present study numerically investigated the effect of human body sited in the driver's place, over the air velocity distribution and over the thermal comfort in a passenger compartment. CFD simulations were made with different angles of the left inlet grill, in both cases, with and without driver presence. In majority of the actual vehicles environment studies, are made without consideration of human body geometry, in this case, the results precision can be affected. The results show that the presence of human body, lead to global changing of the whole flow pattern inside the vehicular cabin. Also, the locations of the maximum velocities are changing with the angle of the guiding vanes. The thermal comfort PMV/PPD indexes were calculated for each case. The presence of human body leads to a more comfortable environment.
\end{abstract}

\section{Introduction}

Thermal comfort is defined by ASHRAE [1] as the condition of mind that expresses physical and psychological satisfaction with the thermal environment. The first approach was made at the beginning of the 19th century, for the buildings environment by Haldane [2], then, during the time several evaluation models were developed. In 1970 Fanger [3] developed in controlled laboratory conditions and with measurement tools available at that time, PMV and PPD indexes which further was embraced by thermal comfort standards. Fanger's indexes were developed in quasi steady-state conditions and were designed for evaluation of the buildings thermal environment.

Researchers focused their attention in direction of thermal comfort of vehicular occupants only in last decades. Thermal comfort of vehicular occupants is gaining more and more importance due to the rising attention towards comfortable mobility, in addition to the growing time that people spend in vehicles (private or public transport)[4]. A comfortable vehicular climate in many cases not only help to reduce the driver stress but also guarantee good visibility by avoiding the fog phenomenon, and contributing to a safer driving. In addition, many independent studies provide evidence of improper thermal environment and its negative influence on the human body $[5,6]$.

The present standards for evaluation of vehicle thermal environment, EN ISO 14505 [7-9], proposed buildings evaluation models, which do not meet the demands of for cabin environment evaluation. Vehicle environment is very different form buildings environment, because on the one hand is affected by more factors (i.e. solar radiation, high air velocity, high differences between interior surfaces)[10]. These factors are neglected by proposed standardized evaluation models. On the other hand vehicle environment is fast transient and non-uniform compared to buildings environment that may be considered quasi steady-state. Other factors who may affect thermal state of vehicular passengers is little space affected to each passenger and complex geometry of this environment. Due to the confined environment (small volume) of the vehicle cabin space, almost any detail of interior geometry is very important. Human body affect vehicles thermal environment though heat dissipation and as an obstacle for airflow. His presence can change temperature and velocity distribution map.

The understanding of flow patterns is still a challenge for nowadays researchers due to the interior cabin complex geometry and also to the ventilation

\footnotetext{
* Corresponding author: ilinca.nastase@gmail.com
} 
system complexity (flow rate, location and geometry of vents) [8]. Additionally, the thermal non-uniformity of the surfaces directly affects the air flow distributions through convective effects. Flow patterns and their effect on thermal sensation are not completely considered by manufacturers or by users, given that flow trajectory might substantially differ from the direction imposed by the guiding vanes of the air vents. This is related on one hand to these previously mentioned convective effects but might be also an in intrinsic characteristic of the air vent itself. Indeed, Lezovic et al [11] studied the flow patterns generated by different positions of the horizontal and vertical guiding vanes of a regular air vent. In their study, the authors used hot wire measurements and smoke visualizations. The results showed that the overall performance of the air diffuser is apparently affected by the individual vanes geometry and their position inside the vent and by the geometry of the supply duct. The influence of different shapes of vents with the same discharge aria over the cabin thermal environment was studied numerically by Ahirrao et al [12]. The results showed that for the same initial conditions a round shape vent might be more efficient than regular square or elliptical vents, leading to a lower mean air temperature and to a better distribution of air velocity and temperature, under certain circumstances. The effects on thermal sensation of different positions of the air vents inside the passenger car were also numerically investigated by Kilic [13]. Three different positions, for the same cooling power, were analyzed under transient conditions. The best results in terms of heat dissipation from the driver's body were achieved using the air vents on the dashboard. The effect of an innovative dynamic air diffusers system over the surfaces temperatures of thermal manikins was studied by Limaye [14]. The authors showed that this active control method might ensure more uniform heat dissipation from the driver's body. Zhang [15] compared in his numerically study the air velocities and temperatures at head, knee and foot level for two cases: in the first case there was no passenger in the car, while in the second case was considered four passengers in cabin. In the second case, higher velocities was found in the rear part of the compartment at the head and foots level and low temperatures, while in the front part at all the levels air velocity was higher for the first case as well as the temperature values.

All these previously cited papers show that the global distribution of the air flows inside the vehicular space plays an important role on thermal sensation, directly via the possibility of heat dissipation of the human body and its ambient, and indirectly through the homogeneity of air temperature and velocity distributions.

This article is a part of a larger study, intended to deepen the knowledge on thermal comfort inside vehicles and its numerical methods of prediction. In this paper the effect of the driver presence and different angles of airflow from an air vent, over the thermal sensation was investigated. In previous papers [16, 17], we presented the setup of the model of a cabin car and we showed that we can reproduce the in-cabin environment without passengers, finding values of indoor thermal variables from the CFD model that were similar to those of experimental measurements. We present in this article, results obtained for the air vent located on the dashboard at the driver's position (left side air vent).

\section{Assessment protocol}

In order to evaluate numerically the cabin thermal environment, the interior of a vehicle was modelled, using dimensions of a real car Renault Megane. After validation of the reference numerical model in the previous study presented in [16], we decided to investigate the influence of the driver presence, over the thermal environment of a vehicle cabin. Therefore, in the vehicle cabin was added a thermal manikin. As a second goal, the air flow direction imposed at the discharge over the global air velocity fields and the air flow patterns in the cabin car is investigated. We present in this article, results obtained for the air vent located on the dashboard at the driver's position (left side air vent) (see Fig. 1).

In this paper we will call Case I - the numerical simulations without a virtual manikin; and Case II - the numerical simulations with a virtual manikin in the cabin. For each of these cases left grill airflow angle was modified on horizontal plane from $0^{\circ}$ to $30^{\circ}$, with one step of $5^{\circ}$ towards the interior cabin. In conclusion 14 numerical simulations were made for each case, each having a different angle.

To evaluate the effects of these different boundary conditions, 16 comparison points was considered (Fig. 2 ), these points being positioned in at the head, chest, knee and foot levels in the place of the passengers.

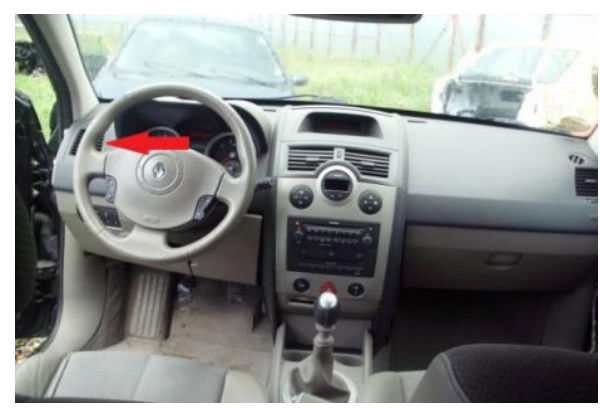

Fig. 1. Renault Megane dashboard, the considered air vent for the parametric variation of the angle of guiding vanes

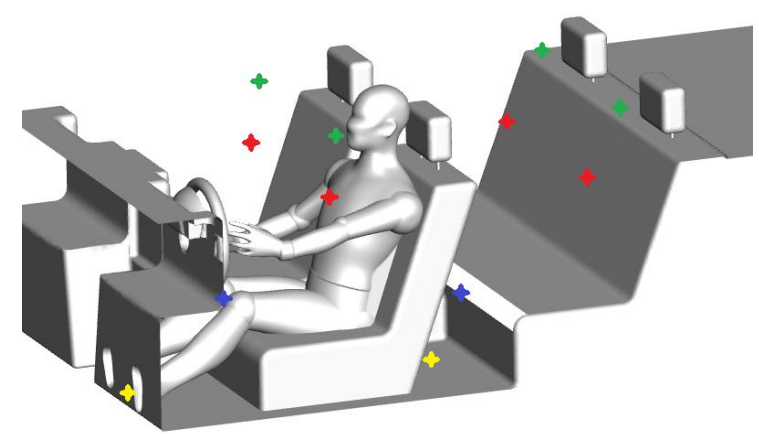

Fig. 2. Considered measurement points at different levels: green - head; red - chest; blue - knee; yellow - foot; 


\subsection{Numerical models}

\subsubsection{Modelling geometry}

The Renault Megane cabin was designed in Catia after drawings from Renault and then imported in Design Modeler from Ansys 18. Several meshes with tetrahedral elements where tested to check the independence of the solution. For the first Case the chosen mesh has 6.14 million elements and is presented in Fig. 3.

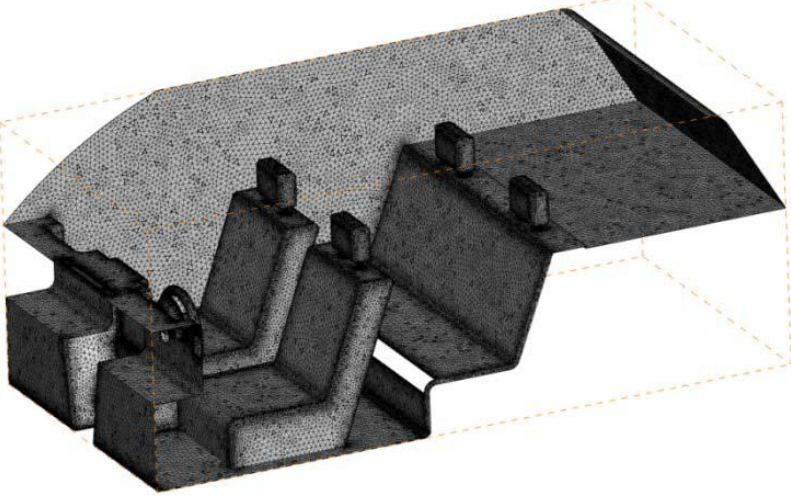

Fig. 3. Mesh detail corresponding to the 6.14 million elements grid for the Case I

For the second Case, we used the vehicle geometry from the Case I, which it had added the geometry of the manikin. After several trials a human body was modified from a freeware version found on internet. The body was modified in Catia and then imported to Design Modeler.

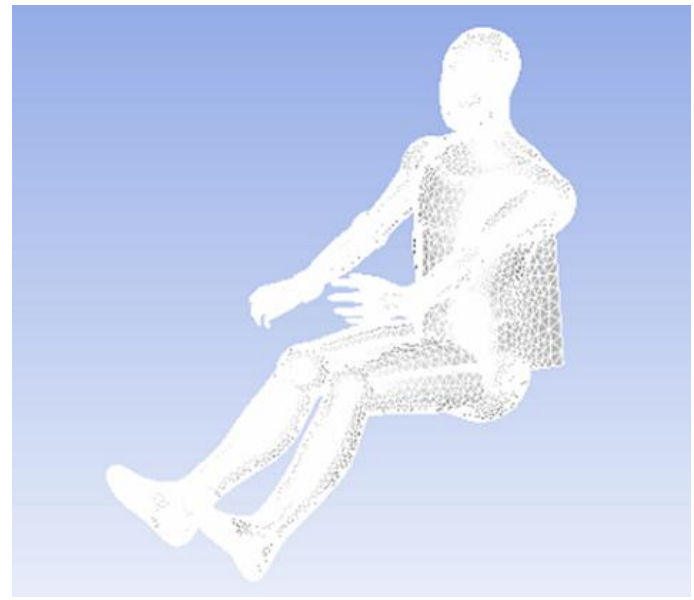

Fig. 4. Virtual thermal manikin

The manikin was first tested in a virtual box (Fig. 5 ) in order to check if it is suitable for meshing, therefore, the evolution of the thermal plume was simulated. Only after several tests it was introduced in the car.

After the insertion of the manikin in the vehicle cabin, it was necessary to re-mesh this case. Several meshes with tetrahedral elements where tested to check the independence of the solution. For the second case the proper mesh have 6.54 million elements and is presented in Fig. 6.

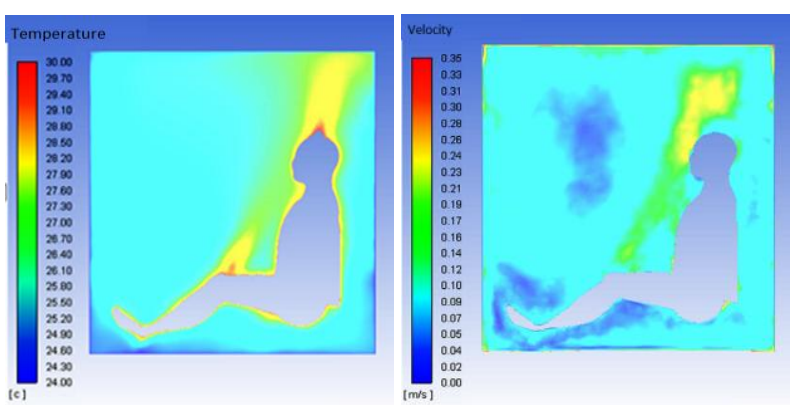

a).

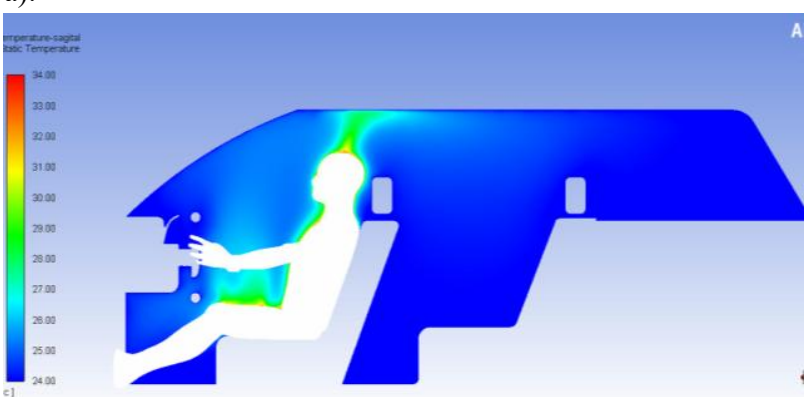

b).

Fig. 5. Natural convection of the body plume: a). - in a test box; b). in vehicle cabin

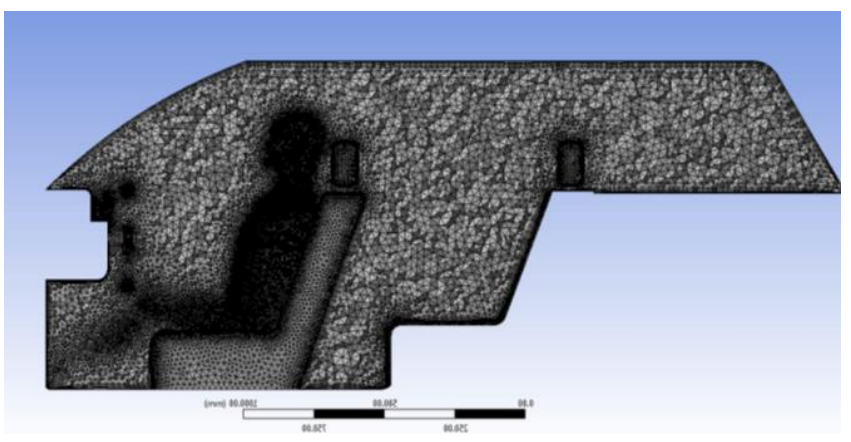

Fig. 6. Mesh detail corresponding to the 6.54 million elements grid for the Case II

For this case with manikin, the very next step will be conceiving a UDF for the direct calculation of $t_{\mathrm{eq}}$ in Fluent. It will serve further to evaluate the local thermal comfort of the human body at the local level. This manikin have a standard height of $1.70 \mathrm{~m}$ and its surface area is $1.81 \mathrm{~m}^{2}$ being suitable for a standing posture and had a total surface area $\left(1.20 \mathrm{~m}^{2}\right)$ for a sitting posture. The rest of the total surface was contact with the solid surfaces of the automobile cabin.

\subsubsection{Boundary conditions}

As the boundary conditions, we imposed a mass flow rate of $0.042 \mathrm{~kg} / \mathrm{s}$ on the central air vents and a mass flow rate of $0.039 \mathrm{~kg} / \mathrm{s}$ on the side air vents. These values are corresponding to the measured values for the 2nd position on the manual control of the ventilation fan speed. We considered this study as isothermal; therefore the value of $23^{\circ} \mathrm{C}$ was imposed for the inlet air 
temperature, internal and external ambient temperature and on the cabin and manikin surfaces temperature.

The Reynolds number at the exit of the central air vents based on stream wise mean velocity and on the equivalent diameter $\left(\mathrm{De}_{1}=0.093 \mathrm{~m}\right)$ was $\mathrm{Re}_{1}=17800$, and for the side air vents $\operatorname{Re} 2=14000(\mathrm{De} 2=0.073 \mathrm{~m})$. The inlet turbulence intensity was imposed for all vents as $4.11 \%$, being calculated using the empirical relation proposed by Jaramillo [13]. For the left side air vent, we modified the angle of the vertical guiding vanes in the horizontal plane from $0^{\circ}$ to $30^{\circ}$, with a $5^{\circ}$ step angle.

\section{Results and discussions}

Fig. 7 and Fig. 8 are presenting the distributions of the velocity magnitude and of the in-plane vectors for the median plane of the driver for both cases. One could observe that the global pattern of the flow inside the cabin is changing dramatically with the variation for only one air vent, and only in the horizontal plane.

Secondly the introduction of the human body, obstruct the air passing on the rear part of cabin, producing vortices in the neck and head zone of the driver. ,Starting with an angle of $20^{\circ}$, the velocity magnitude values in the drivers' chest region are higher than $1 \mathrm{~m} / \mathrm{s}$. In the region of the face and chest for the rear left passenger the velocity magnitude displays values over $0.5 \mathrm{~m} / \mathrm{s}$.

The same observations could be done for the median plane of the passenger Fig. 9 and Fig. 10. The flow pattern changes dramatically with the angle changing, while the presence of the manikin body diminishes air velocity in the rear part of the cabin.

Comparing the velocities found in rear part of the vehicle, high velocities was found in the rear right part of the car comparing with the rear left part. The causes are the inlet angle modification and the presence of the driver.

As a general observation, we note that the maximum values of the velocity magnitude are rather high compared to the limits of the PMV-PPD models from the standards. Moreover, the locations of these maximum values are changing with the angle of the guiding vanes and the presence of the manikin geometry. However, given the high values recorded for the air velocities, the non-suitability of the PMV-PPD model is obvious, giving as a qualitative method of comparison in this case. These values are rather high at several locations when compared to the limits of the PMV-PPD model given in EN ISO 7730[18]. In the same time, the same study should be performed taking into account the thermal components, like the radiative transfer since the creation of recirculation regions with high velocities, resulting from the impinging of side flows on the windows could be benefic through the perspective of an enhanced heat transfer.

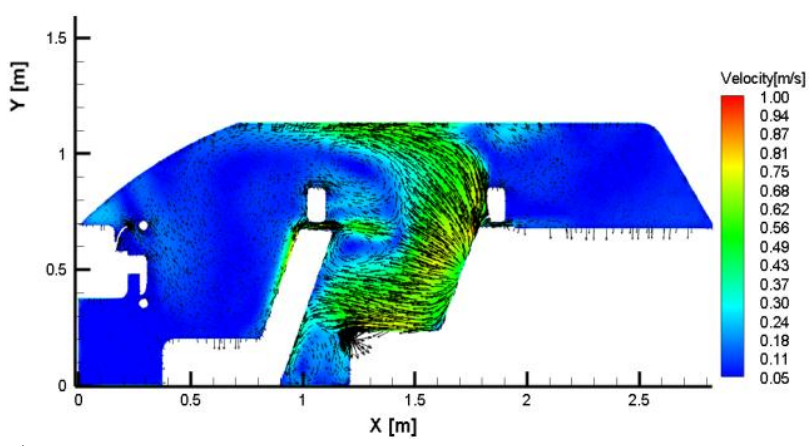

a).

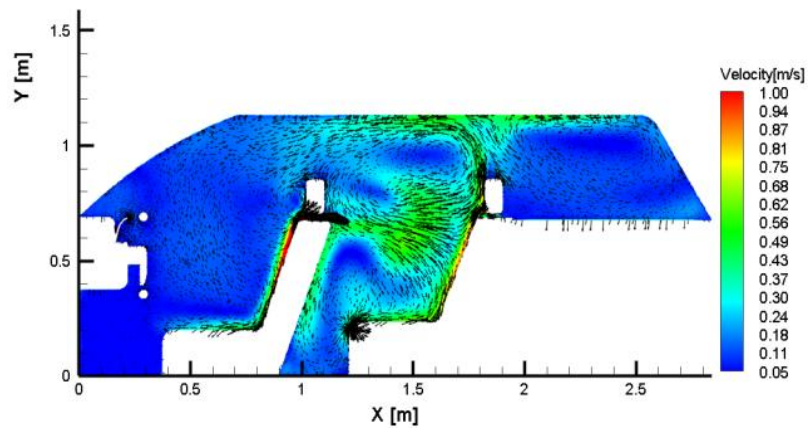

b).

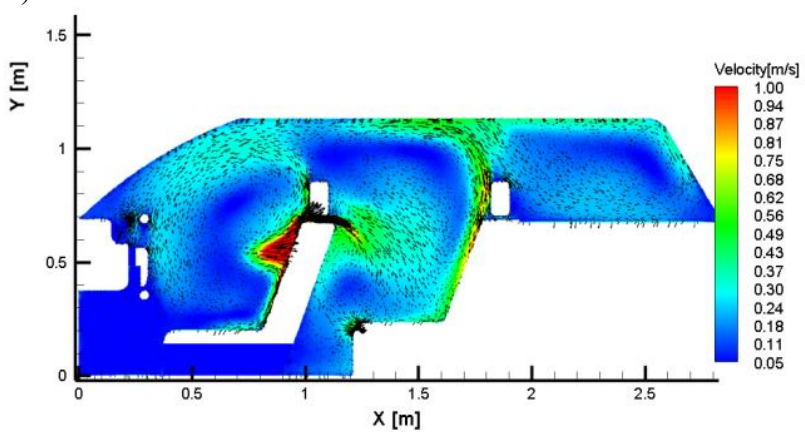

c).

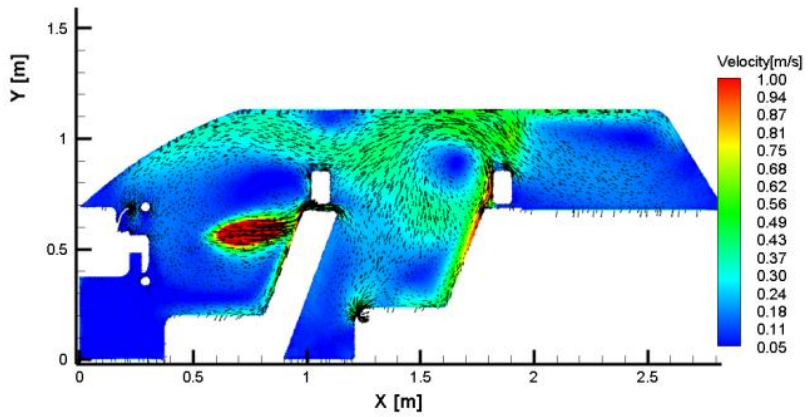

d).

Fig. 7. Distribution of the velocity magnitude and of the in plane vectors for the median plane of the driver: a). $0^{\circ}$; b). $10^{\circ}$; c) $20^{\circ}$; d) $30^{\circ}$, for Case I 


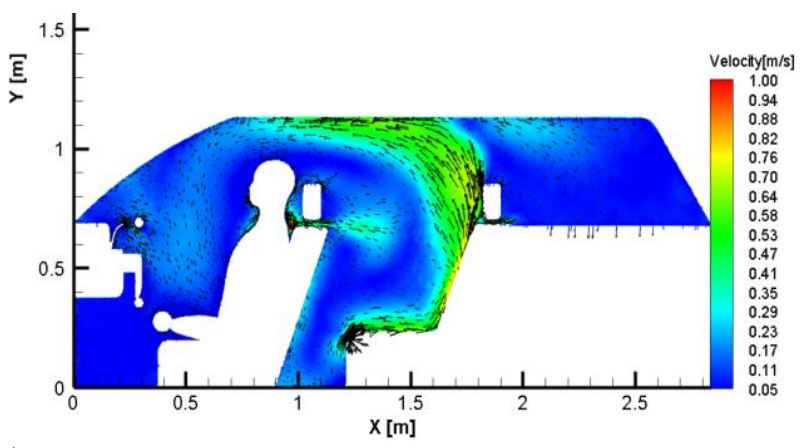

a).

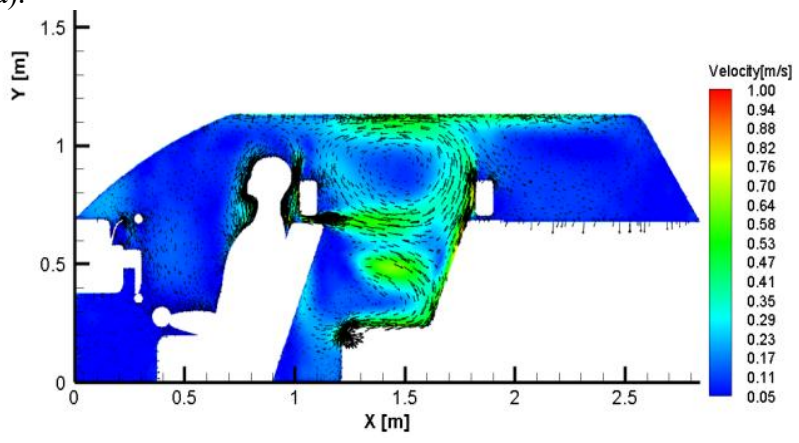

b).

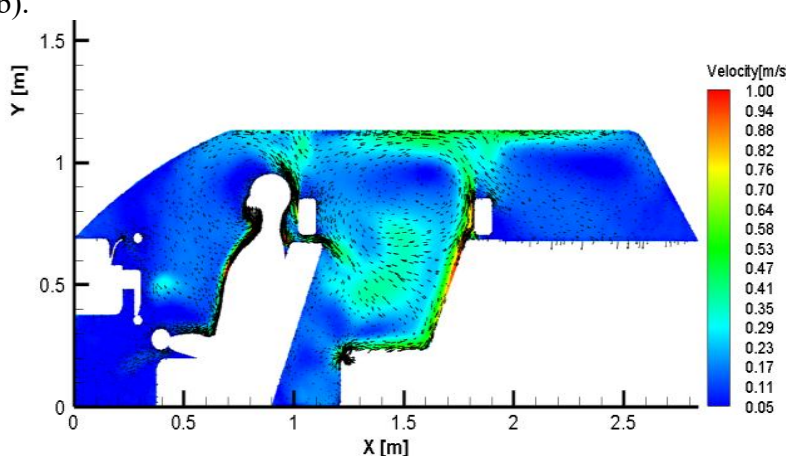

c).

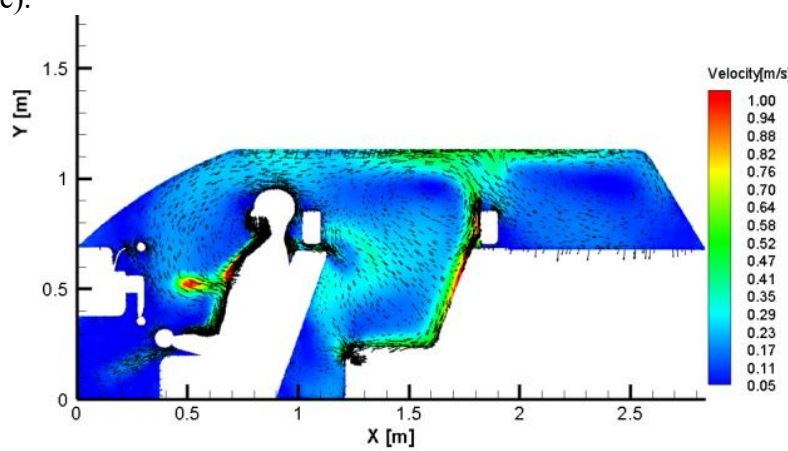

d).

Fig. 8. Distribution of the velocity magnitude and of the in plane vectors for the median plane of the driver: a). $\left.0^{\circ} ; \mathrm{b}\right) .10^{\circ}$; c) $20^{\circ}$; d) $30^{\circ}$, for Case II

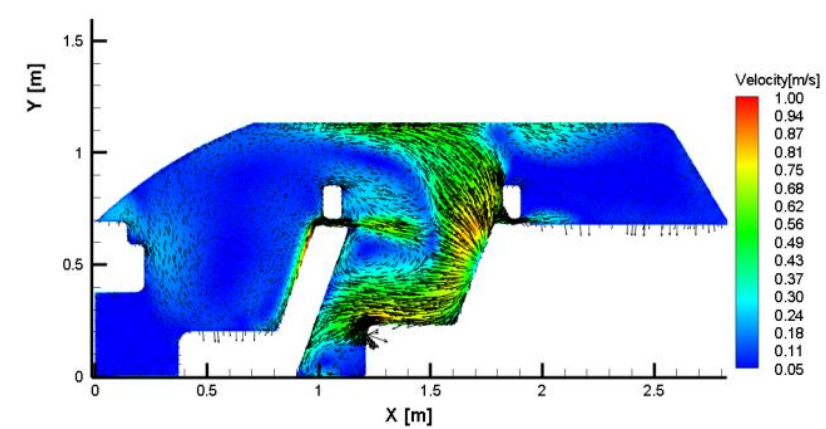

a).

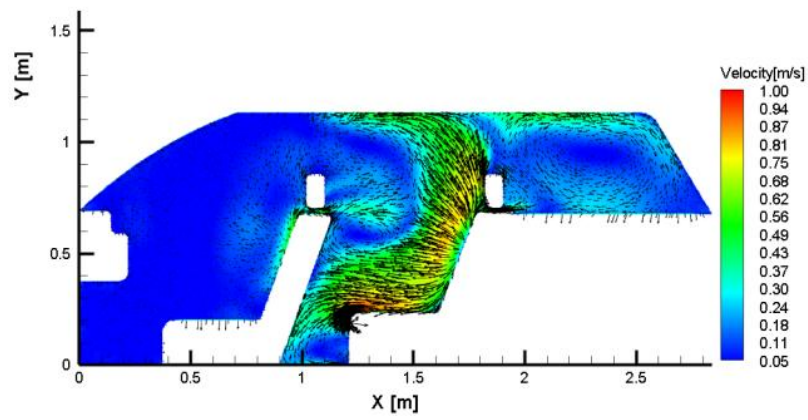

b).

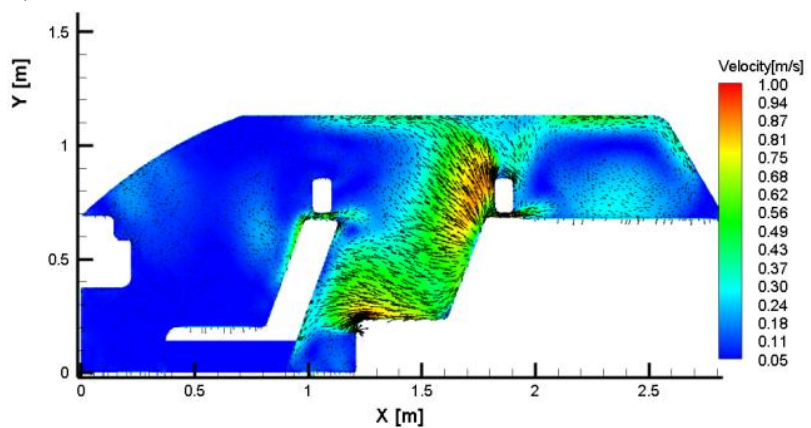

c)

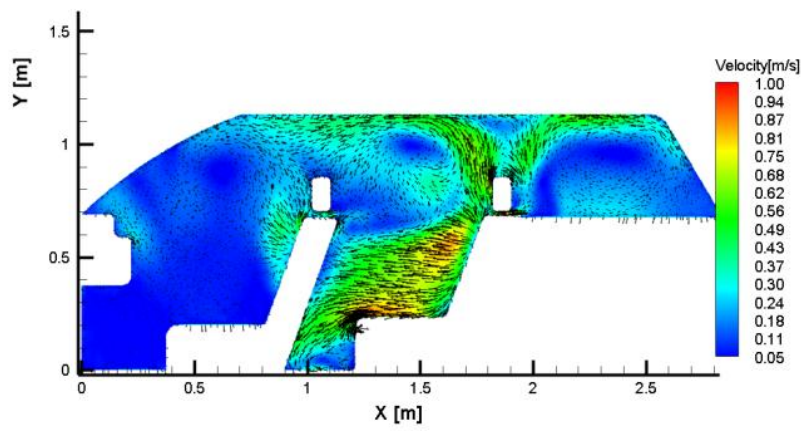

Fig. 9. Distribution of the velocity magnitude and of the in plane vectors for the median plane of the passenger: a). $0^{\circ} ; \mathrm{b}$ ). $10^{\circ}$; c) $20^{\circ}$; d) $30^{\circ}$, for Case I 


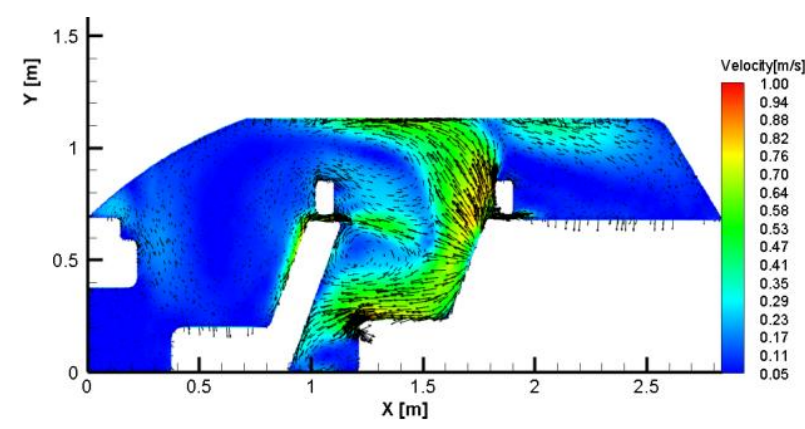

a).

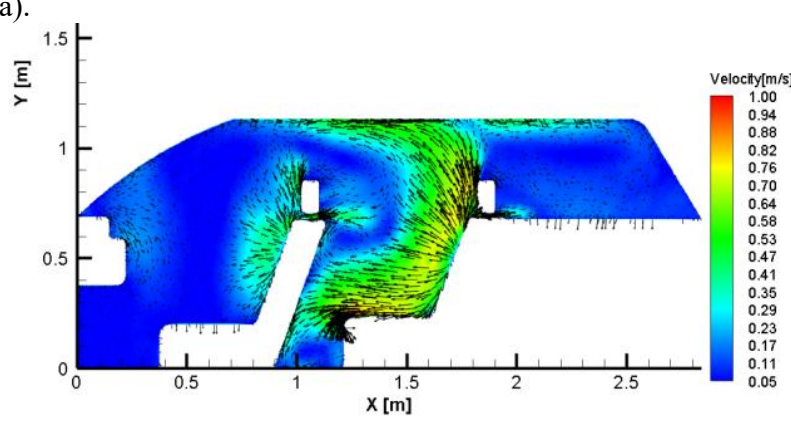

b).

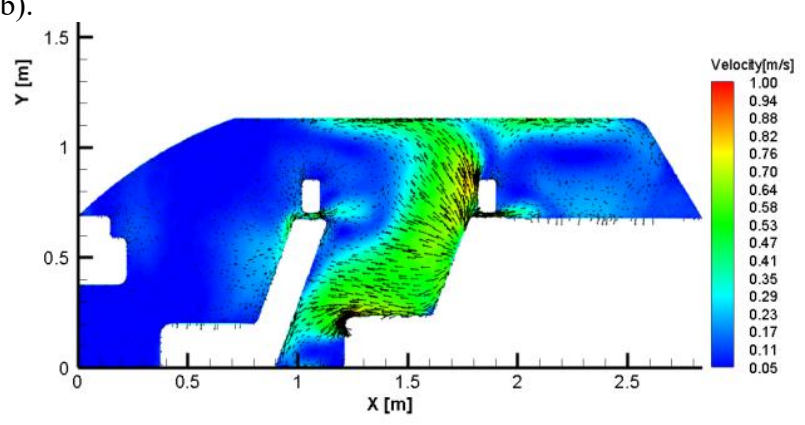

c).

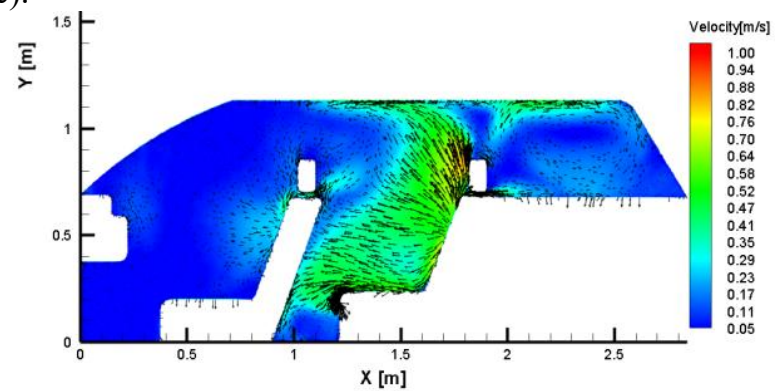

Fig. 10. Distribution of the velocity magnitude and of the in plane vectors for the median plane of the passenger: a). $0^{\circ} ; \mathrm{b}$ ). $10^{\circ}$; c) $20^{\circ}$; d) $30^{\circ}$, for Case II

The horizontal planes from the chest level help us to understand better the effects of the changes.

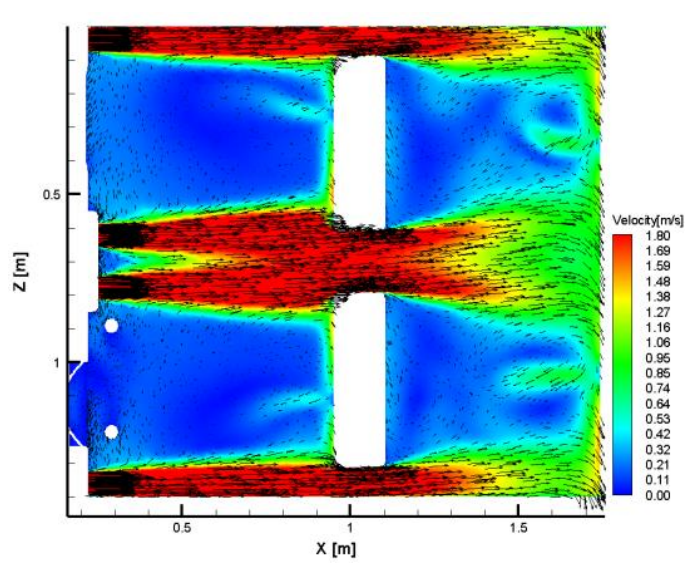

a).

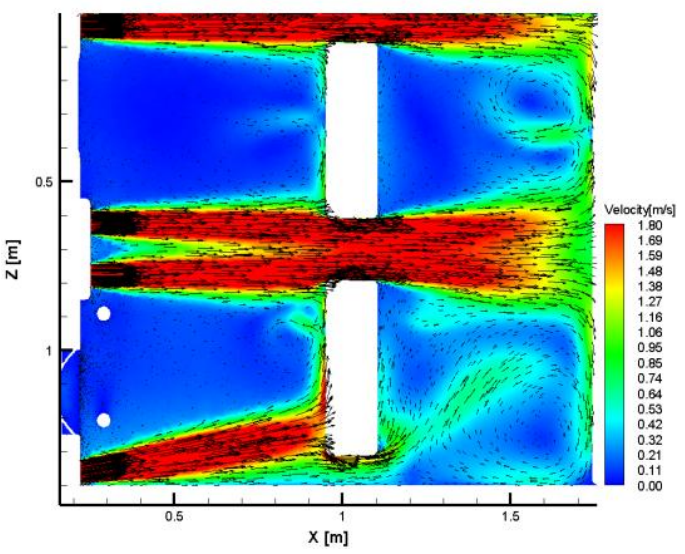

b).

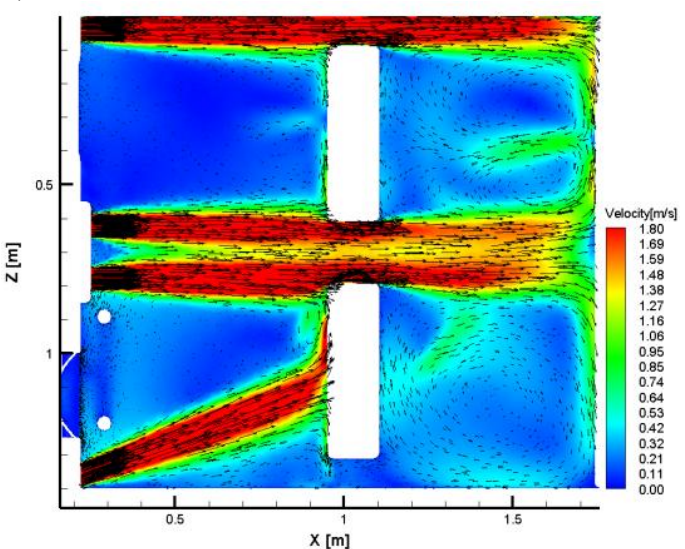

c).

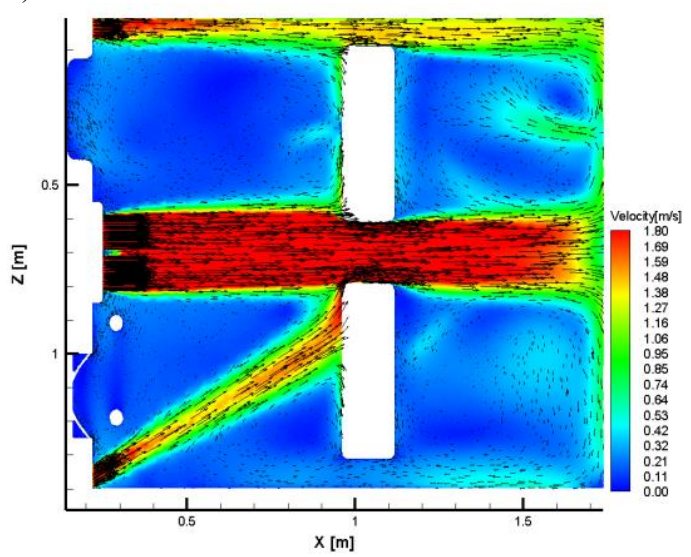

d).

Fig. 11. Distribution of the velocity magnitude and of the in plane vectors for the median plane of the passenger: a). $0^{\circ} ; \mathrm{b}$ ). $10^{\circ}$; c) $20^{\circ}$; d) $30^{\circ}$, for Case I 


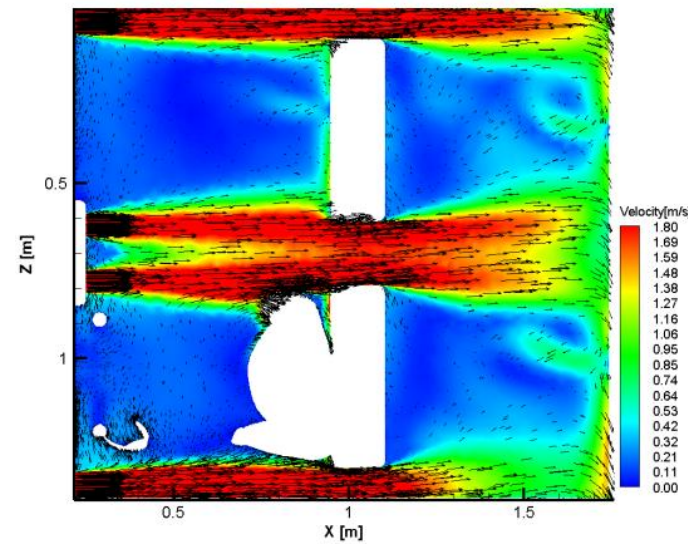

a).

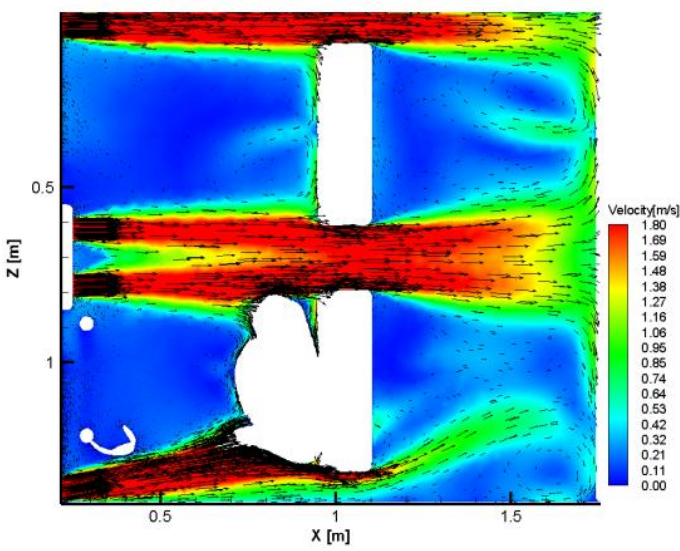

b).

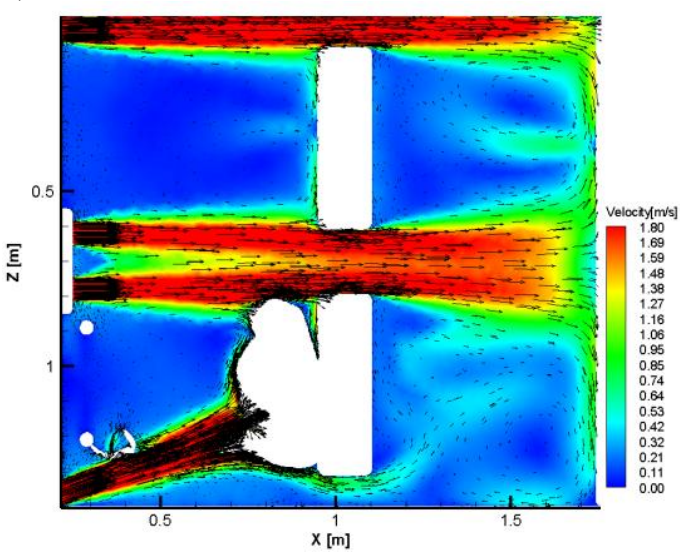

c).

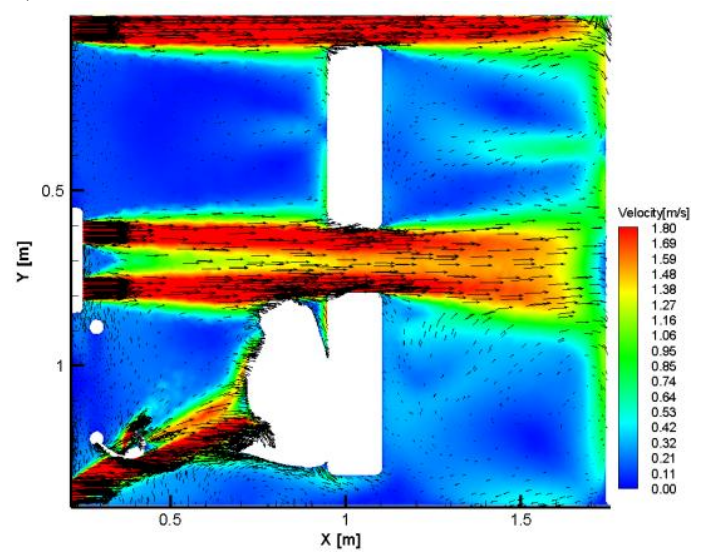

d).

Fig. 12. Distribution of the velocity magnitude and of the in plane vectors for the median plane of the passenger: a). $0^{\circ} ; \mathrm{b}$ ). $10^{\circ}$; c) $20^{\circ}$; d) $30^{\circ}$, for Case II
Table 1. PMV index comparison

\begin{tabular}{|c|cc|cc|cc|cc|}
\hline Point/ & \multicolumn{2}{|c|}{$\mathbf{0}^{\circ}$} & \multicolumn{2}{c|}{$\mathbf{1 0}^{\circ}$} & \multicolumn{2}{c|}{$\mathbf{2 0}^{\circ}$} & \multicolumn{2}{c|}{$\mathbf{3 0}^{\circ}$} \\
parameter & Case I & Case II & Case I & Case II & Case I Case II & Case I Case II \\
\hline D. Head & -0.54 & -0.54 & $\mathbf{- 0 . 5 4}$ & $\mathbf{- 1 . 0 0}$ & -0.54 & -0.54 & -0.54 & -0.58 \\
P. Head & -0.54 & -0.54 & -0.54 & -0.58 & -0.65 & -0.54 & $\mathbf{- 0 . 7 1}$ & $\mathbf{- 0 . 5 4}$ \\
R.R. Head & -1.44 & -1.45 & -1.12 & -1.15 & -0.94 & -0.93 & $\mathbf{- 1 . 0 8}$ & $\mathbf{- 0 . 8 5}$ \\
R.L. Head & -1.50 & -1.56 & -1.53 & -1.54 & -1.59 & -1.50 & $\mathbf{- 1 . 2 3}$ & $\mathbf{- 1 . 5 0}$ \\
D. Chest & -0.54 & -0.54 & $\mathbf{- 0 . 5 8}$ & $\mathbf{- 1 . 0 2}$ & $\mathbf{- 0 . 8 0}$ & $\mathbf{- 1 . 9 5}$ & $\mathbf{- 2 . 0 8}$ & $\mathbf{- 1 . 9 2}$ \\
P. Chest & -0.54 & -0.54 & -0.74 & -0.72 & -0.72 & -0.71 & $\mathbf{- 0 . 6 0}$ & $\mathbf{- 0 . 7 4}$ \\
R.R. Chest & $\mathbf{- 1 . 5 3}$ & $\mathbf{- 0 . 9 0}$ & $\mathbf{- 1 . 1 9}$ & $\mathbf{- 0 . 9 2}$ & -0.94 & -0.99 & $\mathbf{- 1 . 0 7}$ & $\mathbf{- 0 . 9 2}$ \\
R.L. Chest & -1.49 & -1.39 & -1.56 & -1.51 & -1.47 & -1.45 & $\mathbf{- 1 . 6 1}$ & $\mathbf{- 1 . 3 4}$ \\
D. Knee & -0.54 & -0.54 & -0.54 & -0.54 & -0.54 & -0.54 & -0.54 & -0.55 \\
P. Knee & -0.63 & -0.54 & -0.54 & -0.54 & -0.54 & -0.54 & -0.54 & -0.54 \\
R.R. Knee & $\mathbf{- 0 . 9 8}$ & $\mathbf{- 0 . 6 8}$ & $\mathbf{- 0 . 7 7}$ & $\mathbf{- 0 . 9 5}$ & $\mathbf{- 1 . 0 2}$ & $\mathbf{- 0 . 8 7}$ & $\mathbf{- 0 . 8 3}$ & $\mathbf{- 1 . 0 0}$ \\
R.L. Kneen & -1.44 & -1.41 & -1.46 & -1.46 & -1.45 & -1.39 & $\mathbf{- 1 . 4 8}$ & $\mathbf{- 1 . 2 6}$ \\
D. Foot & -0.54 & -0.54 & -0.54 & -0.54 & -0.54 & -0.54 & -0.54 & -0.54 \\
P. Foot & -0.54 & -0.54 & -0.54 & -0.54 & -0.54 & -0.54 & -0.54 & -0.54 \\
R.R. Foot & $\mathbf{- 0 . 5 8}$ & $\mathbf{- 0 . 8 2}$ & -0.72 & -0.68 & -0.72 & -0.80 & $\mathbf{- 0 . 5 4}$ & $\mathbf{- 0 . 7 7}$ \\
R.L. Foot & -0.80 & -0.76 & -0.80 & -0.72 & $\mathbf{- 0 . 5 4}$ & $\mathbf{- 0 . 7 4}$ & -0.54 & -0.54 \\
\hline
\end{tabular}

Table 2. PPD [\%] index comparison

\begin{tabular}{|c|cc|cc|cc|cc|}
$\begin{array}{c}\text { Point/ } \\
\text { parameter }\end{array}$ & \multicolumn{2}{|c|}{$\mathbf{0}^{\circ}$} & \multicolumn{2}{|c|}{$\mathbf{1 0}^{\circ}$} & \multicolumn{2}{|c|}{$\mathbf{2 0}^{\circ}$} & \multicolumn{2}{|c|}{$\mathbf{3 0}^{\circ}$} \\
\hline Case I Case II & Case I & Case II & Case I Case II & Case I & Case II \\
\hline P. Head & 11.23 & 11.23 & $\mathbf{1 1 . 2 4}$ & $\mathbf{2 6 . 1 6}$ & 11.23 & 11.23 & 11.23 & 11.99 \\
R.R. Head & 11.23 & 11.23 & 11.23 & 11.99 & 13.81 & 11.23 & $\mathbf{1 5 . 5 5}$ & $\mathbf{1 1 . 2 3}$ \\
R.L. Head & 58.05 & 48.51 & 31.45 & 32.83 & 23.75 & 23.25 & $\mathbf{2 9 . 9 4}$ & $\mathbf{2 0 . 3 6}$ \\
D. Chest & 11.23 & 11.27 & 52.81 & 53.01 & 55.98 & 51.03 & $\mathbf{3 6 . 7 7}$ & $\mathbf{5 0 . 9 9}$ \\
P. Chest & 11.23 & 11.23 & 16.49 & $\mathbf{2 6 . 9 4}$ & $\mathbf{1 8 . 5 9}$ & $\mathbf{7 4 . 4 5}$ & $\mathbf{8 0 . 4 1}$ & $\mathbf{7 3 . 4 0}$ \\
R.R. Chest & $\mathbf{5 2 . 8 1}$ & $\mathbf{2 2 . 0 8}$ & $\mathbf{3 4 . 8 2}$ & $\mathbf{2 2 . 9 2}$ & 15.93 & 15.65 & $\mathbf{1 2 . 5 7}$ & $\mathbf{1 6 . 6 8}$ \\
R.L. Chest & 50.73 & 45.04 & 54.38 & 51.37 & 49.42 & 48.69 & $\mathbf{2 9 . 2 1}$ & $\mathbf{2 2 . 9 2}$ \\
D. Knee & 11.23 & 11.23 & 11.23 & 11.23 & 11.23 & 11.23 & 11.23 & $\mathbf{4 2 . 7 3}$ \\
P. Knee & 13.33 & 11.23 & 11.23 & 11.23 & 11.23 & 11.23 & 11.23 & 11.23 \\
R.R. Knee & $\mathbf{2 5 . 3 7}$ & $\mathbf{1 4 . 9 0}$ & $\mathbf{1 7 . 6 8}$ & $\mathbf{2 4 . 1 6}$ & $\mathbf{2 6 . 9 4}$ & $\mathbf{2 0 . 9 3}$ & $\mathbf{1 9 . 4 8}$ & $\mathbf{2 6 . 1 6}$ \\
R.L. Knee & 48.05 & 46.19 & 48.97 & 48.97 & 48.51 & 45.39 & $\mathbf{4 9 . 8 6}$ & $\mathbf{3 8 . 2 2}$ \\
D. Foot & 11.23 & 11.23 & 11.23 & 11.23 & 11.23 & 11.23 & 11.23 & 11.23 \\
P. Foot & 11.23 & 11.23 & 11.23 & 11.23 & 11.23 & 11.23 & 11.23 & 11.23 \\
R.R. Foot & $\mathbf{1 1 . 9 9}$ & $\mathbf{1 9 . 3 9}$ & 15.84 & 14.90 & 15.84 & 18.59 & $\mathbf{1 1 . 2 3}$ & $\mathbf{1 7 . 6 8}$ \\
R.L. Foot & 18.59 & 17.32 & 18.59 & 15.84 & $\mathbf{1 1 . 2 3}$ & $\mathbf{1 6 . 7 7}$ & 11.23 & 11.23 \\
& & & & & & & & \\
\hline
\end{tabular}

Knowing the air velocity magnitude values from the numerical model and considering the metabolic rate value of 1 met and clothing insulation of 0.7 clo, the Predicted Mean Vote (PMV) and the Predicted Percentage of Dissatisfied (PPD) indexes were calculated. Tables Table 1 and Table 2 present values for the PMV and PPD indexes obtained at the right of each passenger place in the cabin for respectively the head, the chest, the knees and the feet. It appears from these tables that the most favorable position of the guiding vanes of the studied air vent is for an angle of $0^{\circ}$, knowing that most of PMV and PPD values fall in the acceptable range close to thermal neutrality. As the angle of the guiding vanes of the left air vent increases, values of PMV decreases showing an increased sensation of cooling.

This results in higher percentages of dissatisfied.

For the front passenger head, we could not distinguish a clear trend for the variation of PMV/PPD values, most of them indicating much higher values for the velocity magnitude of air. As for the head region located at the position of the two rear passengers, all values of PMV fall between slightly cool and cool range. From the Table 1 it appears that the PMV values have the tendency to a more comfortable state when the manikin in present than without manikin. Table 2 shows 
that the percentage of dissatisfied is smaller for the second case at $0^{\circ}$ and $30^{\circ}$, with de high difference of $30,73 \%$ for R.R. Chest for $0^{\circ}$; and $14,33 \%$ for R.L. Chest. These differences are due to the manikin hand which intersects the flow from the left air vent. Among the simulations including the human geometry, more comfortable predicted values were achieved with the $10^{\circ}$ angle with the respect of the sensations at tke levels of the head and of the knees.

\section{Conclusions}

One of the conclusions is that even a slight modification of the flow direction, only in the horizontal plane and only for one air vent is leading to the global changing of the whole flow pattern inside the vehicular cabin.

The second general conclusion is related to the presence of human body. As was sown the manikin geometry have a big effect over the air velocity distribution in vehicle compartment. Also any detail of cabin interior that can influence interior thermal environment must to be considered even in parametrical studies.

For air flow rates corresponding to the second position of the manual control of the fan speed, air velocities are rather high compared to the limits of the PMV-PPD models from the standards. Moreover, the locations of the maximum velocities are changing with the presence of the manikin geometry and with the angle of the guiding vanes. In these cases, in our opinion, it appears that global measurement methods for assessing thermal comfort, i.e. the use of a comfort meter placed in the specific point (as in the center) of the cabin is not anymore suitable.

This work was supported by a grant of the Romanian space agency ROSA, QUEST - Advanced air diffusion system of the crew quarters for the ISS and deep space habitation systems, STAR-CDI-C3-2016-577

\section{References}

1. ASHRAE, "Thermal environmental conditions for human occupancy,', ANSI/ASHRAE Standard 55-2013, American Society of Heating, Refrigerating and Air-Conditioning Engineers, Atlanta, GA. 2013.

2. Haldane, J.S., The Influence of High Air Temperatures. The Journal of Hygiene, 1905. 5: p. 494-513.

3. Fanger, P.O., ed. Thermal Comfort-Analysis and Applications in Environmental Engineering. ed. C.D.T. Press. 1970.

4. Cristiana CROITORU, et al., Thermal comfort models for indoor spaces and vehicles - current capabilities and future perspectives. Renewable \& Sustainable Energy Reviews, accepted for publication, 2015.
5. Chen, A. and V.W.C. Chang, Human health and thermal comfort of office workers in Singapore. Building and Environment, 2012. 58(Supplement C): p. 172-178.

6. Ormandy, D. and V. Ezratty, Health and thermal comfort: From WHO guidance to housing strategies. Energy Policy, 2012. 49(0301-4215): p. 116-121.

7. ISO, Ergonomics of the thermal environment Evaluation of thermal environments in vehicles Part 3: Evaluation of thermal comfort using human subjects, in ISO 14505-3:2006. 2006.

8. ISO, Ergonomics of the thermal environment Evaluation of thermal environments in vehicles - Part 2: Determination of equivalent temperature in ISO 14505-2:2006. 2006.

9. ISO, Ergonomics of the thermal environment Evaluation of thermal environments in vehicles Part 1: Principles and methods for assessment of thermal stress, in ISO 14505-1:2007. 2007.

10. jonsson, J., Including Solar Load in CFD Analysis of Temperature Distribution in a Car Passenger Compartment. 2007, Lulea University of Technology: Sweden.

11. Ležovič, T., et al., HVAC automotive vents evaluation and their performance. HVAC\&R Research, 2013. 19(8): p. 1073-1082.

12. Ahirrao, A.K., et al., Effect of Vent Shape on Thermal Comfort of Passengers in a Car. SASTECH 2011. 10(2): p. 21-28.

13. Kiliç, M. and G. Sevilgen, The effects of using different type of inlet vents on the thermal characteristics of the automobile cabin and the human body during cooling period. The International Journal of Advanced Manufacturing Technology, 2012. 60(5): p. 799-809.

14. Limaye, V.M., et al., Design of Dynamic Airvents and Airflow Analysis in a Passenger Car Cabin. SASTECH, 2012. 11(1): p. 41-48.

15. Zhang, H., et al., Studies of air-flow and temperature fields inside a passenger compartment for improving thermal comfort and saving energy. Part II: Simulation results and discussion. Applied Thermal Engineering, 2009. 29(10): p. 2028-2036.

16. Danca, P., et al., On the Possibility of CFD Modeling of the Indoor Environment in a Vehicle. Energy Procedia, 2017. 112(Supplement C): p. 656-663.

17. Bode, F., et al. The influence of the Inlet angle of vehicle air diffuser on the thermal comfort of passengers. in 2017 International Conference on ENERGY and ENVIRONMENT (CIEM). 2017.

18. ISO, E., ISO 7730 - Ergonomics of the thermal environment-Analytical determination and interpretation of thermal comfort using calculation of the PMV and PPD indices and local thermal comfort criteria. 2005. 